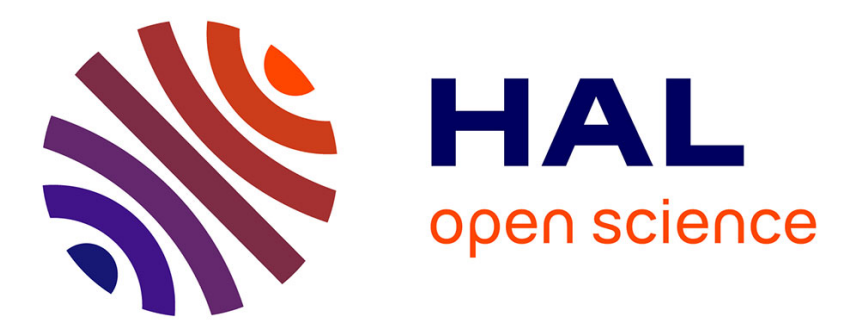

\title{
Transport properties of Ti-Ni-Zr films grown by pulsed laser deposition
}

Olivier Boffoué, Bertrand Lenoir, Alexandre Jacquot, Valerie Brien, Christine Bellouard, Anne Dauscher

\section{- To cite this version:}

Olivier Boffoué, Bertrand Lenoir, Alexandre Jacquot, Valerie Brien, Christine Bellouard, et al.. Transport properties of Ti-Ni-Zr films grown by pulsed laser deposition. Solid State Communications, 2004, 132 (3-4), pp.209-212. 10.1016/j.ssc.2004.07.037 . hal-02882474

\section{HAL Id: hal-02882474 \\ https://hal.science/hal-02882474}

Submitted on 6 Sep 2021

HAL is a multi-disciplinary open access archive for the deposit and dissemination of scientific research documents, whether they are published or not. The documents may come from teaching and research institutions in France or abroad, or from public or private research centers.
L'archive ouverte pluridisciplinaire HAL, est destinée au dépôt et à la diffusion de documents scientifiques de niveau recherche, publiés ou non, émanant des établissements d'enseignement et de recherche français ou étrangers, des laboratoires publics ou privés. 
TOQOTETHSWORK

[1] Q Boffoué, B Lenair, A Jacquod, V. Bien, C. Bellouard, A Dauscher, Transport properties of Ti-N-Zr films grown by pulsed laser deposition, Solid State Commun 132 (2004) 209-212 https//doi.org/10.1016/..ssc.2004.07.037, hal-02882474.

THANKYOU

\title{
Transport properties of Ti-Ni-Zr films grown by pulsed laser deposition
}

Olivier Boffoué a,\#, Bertrand Lenoir $^{\mathrm{a}}$, Alexandre Jacquot ${ }^{\mathrm{a}}$, Valérie Brien ${ }^{\mathrm{b},+}$, Christine Bellouard $^{\mathrm{a}}$, Anne Dauscher ${ }^{\mathrm{a}, *}$

aLaboratoire de Physique des Matériaux, UMR 7556, CNRS-INPL-UHP,

ENSMN, Parc de Saurupt, F-54042 Nancy, France

${ }^{\text {b} L a b o r a t o i r e ~ d e ~ S c i e n c e ~ e t ~ G e ́ n i e ~ d e s ~ M a t e ́ r i a u x ~ e t ~ d e ~ M e ́ t a l l u r g i e, ~ U M R ~ 7584, ~ C N R S-I N P L, ~}$ ENSMN, Parc de Saurupt, F-54042 Nancy, France

\begin{abstract}
Quasicrystalline $\mathrm{Ti}_{41.5} \mathrm{Ni}_{17} \mathrm{Zr}_{41.5}$ thin films have been synthesized at different temperatures by pulsed laser deposition from a Nd:YAG laser. Electrical resistivity, Hall coefficient, magnetoresistance and thermopower measurements have been conducted in the 4.4-300 K or 70-300 $\mathrm{K}$ temperature range. $\mathrm{Ti}_{41.5} \mathrm{Ni}_{17} \mathrm{Zr}_{41.5}$ quasicrystals are characterized by a high electrical conductivity, an order of magnitude higher than in other quasicrystals, independently of their morphology and microstructure. Hall measurements indicate that the films have a high carrier concentration. Thermoelectric powers in $\mathrm{Ti}_{41.5} \mathrm{Ni}_{17} \mathrm{Zr}_{41.5}$ have relatively small magnitudes and the values have been found to depend on the microstructure.
\end{abstract}

PACS numbers: 81.15.Fg, 61.44.Br, 73.50.-h

Key words: A. Thin Films; D. Transport Properties, Quasicrystals

* Corresponding author, phone: 33(0)383584170, fax: 33 (0)383579794, e-mail: dauscher@mines.inpl-nancy.fr

\# Present address: Université de Cocody, UFR STRM, 01 BP 3306, Abidjan 01, Côte d'Ivoire

+ Present address: Laboratoire de Physique des Milieux Ionisés et Applications, UMR 7040, Université Henri Poincaré, Faculté des Sciences et Techniques, B.P. 239, F-54506 Vandoeuvre lès Nancy Cedex, France 


\section{Introduction}

Quasicrystalline alloys have been discovered in 1984 by Shechtman et al. [1]. This class of materials, which exists in a variety of chemical systems, exhibits the particularity to crystallize in forbidden rotational symmetries structures (icosahedral, decagonal...) and to display a long-range aperiodic order not compatible with three-dimensional translation.

A constant effort has been devoted to the attainment of thermodynamically stable quasicrystals of high structural quality and to the understanding of their unusual and interesting chemical and physical properties, in relation with potential applications $[2,3]$. Deviations from standard temperature and composition dependences of the transport coefficients make that quasicrystalline and approximant alloys are positioned as intermediate materials between metals and semiconductors. [4, and refs therein]. Long-range quasiperiodicity, local atomic environment, or combined effects have been given as the possible origin of these particular features. Most of the experimental and theoretical works concerning transport properties has been conducted with Al-based materials, while Ti-based materials have not received much attention yet $[5,6]$.

The aim of our work was to contribute to the study of the physical properties of the Ti-Ni-Zr icosahedral quasicrystalline phase that has attracted much attention until now for its ability to absorb reversibly large amounts of hydrogen making it an excellent candidate for constitutive materials in battery [7-9]. For these particular applications, the materials should be used in the thin film form. We previously showed that pulsed laser deposition (PLD) is an appropriate method to synthesize thermodynamically stable quasicrystalline Ti-Ni-Zr layers $[10,11]$.

In this letter, we report on the electrical properties and thermopower measurements of $\mathrm{Ti}_{41.5} \mathrm{Ni}_{17} \mathrm{Zr}_{41.5}$ quasicrystalline films prepared by PLD at different substrate temperature.

\section{Experimental}

The deposition of the thin films was carried out in a high vacuum stainless steel chamber already described in [10], under a base pressure of $10^{-7}-10^{-8}$ mbar. The films were grown at different deposition temperatures $\mathrm{T}_{\mathrm{s}}(298,373$ and $533 \mathrm{~K})$ onto glass substrates fixed parallel to the target at a distance of $45 \mathrm{~mm}$. The Ti-Ni-Zr targets of $18 \mathrm{~mm}$ in diameter were cut from an ingot prepared by radio-frequency melting. They were freshly polished before each new ablation. A Quantel Nd:YAG laser $(\lambda=1064 \mathrm{~nm}, \tau=10 \mathrm{~ns}, 10 \mathrm{~Hz}$ repetition rate) was used as the ablation source. The laser fluence was fixed at $72 \mathrm{~J} / \mathrm{cm}^{2}$.

The electrical resistivity and the thermoelectric power of both the layers and the target were measured simultaneously in the temperature range 77-310 $\mathrm{K}$ on a home-built sample holder similar to that developed by Stölzer et al. [12]. For the films, the geometry of the samples was defined by the shape of the mask through which the film was deposited. It consisted of a $20 \mathrm{x}$ $3 \mathrm{~mm}^{2}$ rectangular strip with tabs for potential leads. Film thickness was determined by mechanical profilometer measurements performed in the neighbourhood of the voltage leads. The electrical contacts to the sample were made with silver paste. The resistance was measured by a dc standard four-probe resistance technique using current reversals to subtract the thermal voltages. To measure the thermopower of the samples, a differential method has been used. Two small copper-constantan thermocouples (70 $\mu \mathrm{m}$ in diameter) were pressed against the sample by springs. A temperature difference $\Delta \mathrm{T}(<2 \mathrm{~K})$, either positive or negative, was created on the sample by the alternating use of two small heaters in order to 
produce the thermoelectric voltage $\Delta \mathrm{V}$. A least mean square linear regression was applied on the $\Delta \mathrm{V}-\Delta \mathrm{T}$ data to determine the slope and to extract the thermopower. All data were taken using high-speed computer data acquisition software and instrumentation.

Electrical resistivity, transverse magnetoresistance and Hall measurements of the layers were also conducted from $5-300 \mathrm{~K}$ in a Quantum Design cryostat using an ac current at a frequency of $30 \mathrm{~Hz}$. For these experiments, we also used rectangular shaped sample strips with tabs defined by a mask, but having a different size than previously $\left(8 \times 2 \mathrm{~mm}^{2}\right)$. In the case of the electrical resistivity, a good agreement of the two measurements performed on the two different experimental set-ups was observed in the temperature range $80-300 \mathrm{~K}$.

\section{Results and discussion}

All the films investigated show a similar thickness of about $700 \mathrm{~nm}$. Electron probe microanalysis measurements show that the $\mathrm{Ti}_{41.5} \mathrm{Ni}_{17} \mathrm{Zr}_{41.5}$ composition is reached within a 1 at. \% accuracy, independently of the substrate temperature $\mathrm{T}_{\mathrm{s}}$ during growth. This composition was identified by Kelton et al. [9] as being the nominal composition of the icosahedral phase. Non congruent transfer of stoichiometry from the target to the substrate was shown to occur, contrarily to what is generally expected from the PLD method [10]. The observed loss of Ti explains why a target of nominal $\mathrm{Ti}_{45} \mathrm{Ni}_{17} \mathrm{Zr}_{38}$ composition has been used to ensure the attainment of the seeked composition. This target was made of several phases: mainly the icosahedral phase, the approximant phase of the icosahedral phase (phase W) and Laves phases.

Combined TEM and X-ray diffraction investigations revealed that the films are quasicrystalline, but that their morphology and microstructure are quite different, depending on the substrate temperature. X-ray patterns are displayed in figure 1. The sample deposited at the highest temperature $\left(\mathrm{T}_{\mathrm{s}}=533 \mathrm{~K}\right)$ is made of the icosahedral phase under the shape of around $50 \mathrm{~nm}$ wide textured columns constituting around $80 \%$ in volume of the $700 \mathrm{~nm}$ thick film. The columns lay on an underlying nano-quasicrystalline domain. The 5-fold axis of the icosahedral structure statistically matches with the growth direction. The film prepared at 373 $\mathrm{K}$ is essentially made of nanocrystallites whose statistical size is around $3 \mathrm{~nm}$. The film prepared at $298 \mathrm{~K}$ is also made of nanocrystallites. The difference between this structure (prepared at $298 \mathrm{~K}$ ) and the one deposited at $373 \mathrm{~K}$ is that the nanoparticles are statistically smaller $(2 \mathrm{~nm})$ and that they might be embedded in an amorphous matrix. More detailed information about the structure investigations of the films is reported elsewhere [11].

The room-temperature value of the electrical conductivity $\sigma$ of the Ti-Ni-Zr layers is about $4850 \Omega^{-1} \cdot \mathrm{cm}^{-1}$ whatever $T_{\mathrm{s}}$ is, while for the target $\sigma \sim 5300 \Omega^{-1} \cdot \mathrm{cm}^{-1}$. The deviation to the value of the films is attributed to the difference in both the chemical composition and structural disorder. Compared to the other most investigated quasicrystalline systems containing transition metals like $\mathrm{Al}-\mathrm{Cu}-(\mathrm{Fe}, \mathrm{Re}, \mathrm{Ru})$ or $\mathrm{Al}-\mathrm{Pd}-(\mathrm{Mn}, \mathrm{Re}), \sigma$ is one or two orders of magnitude higher in the $\mathrm{i}-\mathrm{Ti}_{41.5} \mathrm{Ni}_{17} \mathrm{Zr}_{41.5}$ alloy at room temperature. Figure 2 shows the temperature dependence of the normalized conductivities $\sigma(\mathrm{T}) / \sigma(300 \mathrm{~K})$ for the films and the target. The temperature coefficient $\alpha$ of the conductivity is positive for the films whatever $T_{\mathrm{s}}$ is. This result is consistent with the $\sigma-\alpha$ Mooij correlation [13] observed in lowconductivity metallic alloys and with previous results obtained by Zavaliche et al. [5] on rapidly quenched Ti-Ni-Zr ribbons, but is in disagreement with the recent study of Azhazha et al. [6] where $\alpha$ was found negative. We also observed a negative temperature coefficient $\alpha$ for 
the target but we believe that it is correlated to the low target quality containing crystalline phases.

Little differences are observed in the behaviour of $\sigma(\mathrm{T}) / \sigma(300 \mathrm{~K})$ for the films prepared at 298 and $373 \mathrm{~K}$, likely due to their very similar morphology and microstructure. For the film deposited at $533 \mathrm{~K}$, that shows larger icosahedral domains, it is seen that the normalized conductivity becomes slowly temperature dependent. One general trend observed in quasicrystals is that the conductivity decreases when the perfection of the sample increases [14]. Figure 2 seems to suggest the contrary. If we exclude a compositional effect and the presence of minor impurity phases in the films, the deviation to the usual behaviour should find its origin in the different microstructure. Effects linked to the anisotropy could play a role since the film becomes more textured with an orientation of the 5-fold axis perpendicular to the substrate as $\mathrm{T}_{\mathrm{s}}$ increases [11].

The temperature dependence of the normalized conductivity of the films was approximated by a power law following the procedure proposed in [15]. For $\mathrm{T}_{\mathrm{s}}=298$ and $373 \mathrm{~K}$, the exponent $\mathrm{n}$ is close to 1.5 for $\mathrm{T}<60 \mathrm{~K}$ suggesting a semi-metallic-like behaviour, and to 0.6 for $\mathrm{T}>60$ $\mathrm{K}$ suggesting a weak localization behaviour. For the film prepared at $\mathrm{T}_{\mathrm{s}}=533 \mathrm{~K}$, two zones can also be observed: for $\mathrm{T}<100 \mathrm{~K}, \mathrm{n} \sim 0.8$, and at higher temperatures $\mathrm{n} \sim 0.5$. These crossovers of the changes in behaviour of the conductivity versus temperature from one conduction mechanism to another have also been observed by Zavaliche et al. [5] and have been attributed to a "depletion" of the electronic states near the Fermi level with increasing temperature.

The Hall coefficient of the films was found to be field independent in the range of fields, B, investigated $(-4 \leq \mathrm{B} \leq+4 \mathrm{~T})$ over the entire temperature range studied. The Hall coefficient is low and positive whatever the substrate temperature $\mathrm{T}_{\mathrm{s}}$ is. The Hall carrier concentration at room temperature is $\sim 8-9 \times 10^{22} \mathrm{~cm}^{-3}$ for films grown at $\mathrm{T}_{\mathrm{s}}=298$ and $373 \mathrm{~K}$ and is lower for $\mathrm{T}_{\mathrm{s}}=533 \mathrm{~K}\left(\sim 5.7 \times 10^{22} \mathrm{~cm}^{-3}\right)$. These values are typical of those observed in disordered metallic glasses containing transition metals [16]. The Hall carrier concentration is slowly temperature dependent for $\mathrm{T}_{\mathrm{s}}=298$ and $373 \mathrm{~K}$ (variations are less than $10 \%$ ) over the temperature range investigated. The deviation from the metallic-glass behaviour is more pronounced in the case of $\mathrm{T}_{\mathrm{s}}=533 \mathrm{~K}$ with variations of the order of $30 \%$ as illustrated in figure 3 .

The transverse magnetoresistance, $\Delta \rho / \rho$, of the films was found to be positive and remained very small in the range of fields studied. For example, at $5 \mathrm{~K}, \Delta \rho / \rho \sim 0.016 \%$ and $0.031 \%$ for $\mathrm{T}_{\mathrm{s}}=298$ and $373 \mathrm{~K}$ respectively. Higher values have been observed for the films prepared at $\mathrm{T}_{\mathrm{s}}=533 \mathrm{~K}$ (figure 4 ).

Figure 5 shows the thermopower $\mathrm{S}$ as a function of temperature for the Ti-Ni-Zr layers and the target. The films have small thermopower values, typical of a metal; $S$ displays essentially linear temperature dependence, as also reported before [5,17], with positive $S$ values consistent with the positive Hall coefficient measured. The value reached at room temperature strongly depends on the microstructure of the layers: $2.7 \mu \mathrm{V} / \mathrm{K}$ for the films prepared at $T_{\mathrm{s}}=$ 298 and $373 \mathrm{~K}$ and $8.3 \mu \mathrm{V} / \mathrm{K}$ for $\mathrm{T}_{\mathrm{s}}=533 \mathrm{~K}$. The thermopower of the target varies also linearly but the value starts out negative at low temperatures, crosses zero, and has a room temperature value of $0.7 \mu \mathrm{V} / \mathrm{K}$.

The linear temperature dependence of the thermopower $S$ is indicative of a diffusion thermopower. Sensitivity of $\mathrm{S}(\mathrm{T})$ to both composition and microstructure changes can be 
related to the special sensitivity of the thermopower to the details in the density of states around the Fermi Level.

\section{References}

[1] D. Schechtman, I. Blech, D. Gratias, J. W. Cahn, Phys. Rev. Lett. 53 (1984) 1951

[2] Quasicrystals, Edited by J.-M. Dubois, P. Thiel, A.P. Tsai, and K. Urban (Materials Research Society, Pittsburgh, PA, 1999), vol. 553.

[3] J.-M. Dubois, Materials Science and Engineering, 294-296 (2000) 4

[4] E. Macia, J. Appl. Phys., 93 (2003) 1014

[5] F. Zavaliche, R. Manaila, R. Haberkern, P. Häussler, S.J. Poon, A. Belu-Marin, A. Devenyi, Phys. Stat. Sol., 218 (2000) 485

[6] V. Azhazha, G. Khadzhay, S. malikhin, B. Merisov, A. Pugachov, Physics Letters A 319 (2003) 539

[7] K.F. Kelton, P.C. Gibbons, Mat. Res. Soc. Bull., 22 (1997) 69

[8] A.M. Viano, R.M. Stroud, P.C. Gibbons, A.F. McDowell, M.S. Conradi, K.F. Kelton, Phys. Rev. B, 51 (1995) 12026

[9] A. Takasaki, C.H. Han, Y. Furuya, K.F. Kelton, Phil. Mag. Lett., 82 (2002) 353

[10] V. Brien, A. Dauscher, P. Weisbecker, F. Machizaud, Appl. Phys. A, 76 (2003) 187

[11] V. Brien, A. Dauscher, P. Weisbecker, J. Ghanbaja, F. Machizaud, J. Crystal Growth, 256 (2003) 407

[12] M. Stölzer, V. Bechstein, J. Meusel, Proceedings of the $4^{\text {th }}$ European Workshop on Thermoelectrics, Madrid, 1998, p. 97.

[13] J. H. Mooij, Phys. Stat. Sol. (a) 17 (1973) 321

[14] J.S. Poon, Adv. Phys., 41 (1992) 303

[15] R. Rosenbaum, J. Genossar, J. Phys. Condens. Matter, 9 (1997) 901

[16] M.A. Howson, B.L. Gallagher, Phys. Rep., 170 (1988) 265

[17] B. D. Biggs, S.J. Poon, N.D. Munirathnam, Phys. Rev. Lett., 65 (1990) 2700 


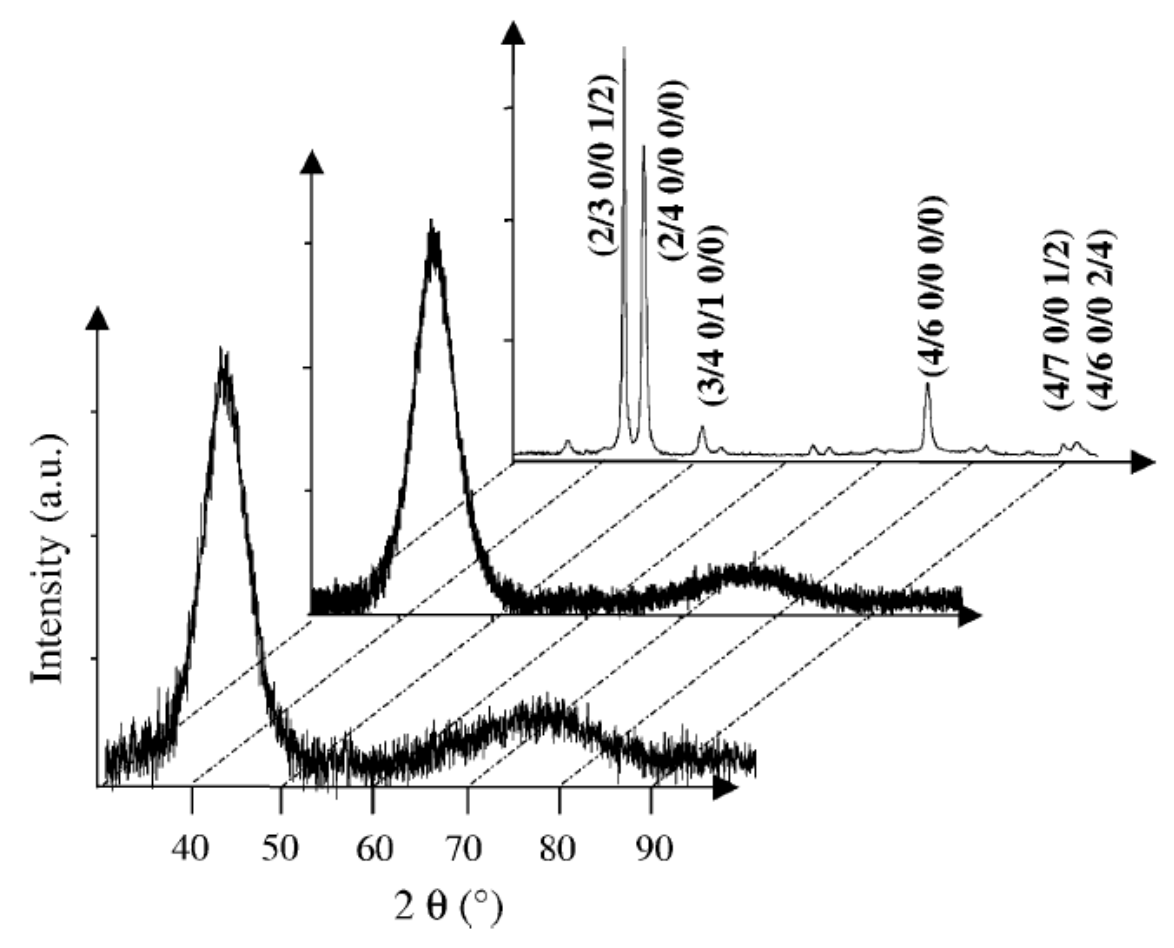

Figure 1 : X-ray diffraction patterns of the films prepared at a/ $298 \mathrm{~K}$, b/ $373 \mathrm{~K}$, and c/ $533 \mathrm{~K}$. a.u. stands for arbitrary units. 


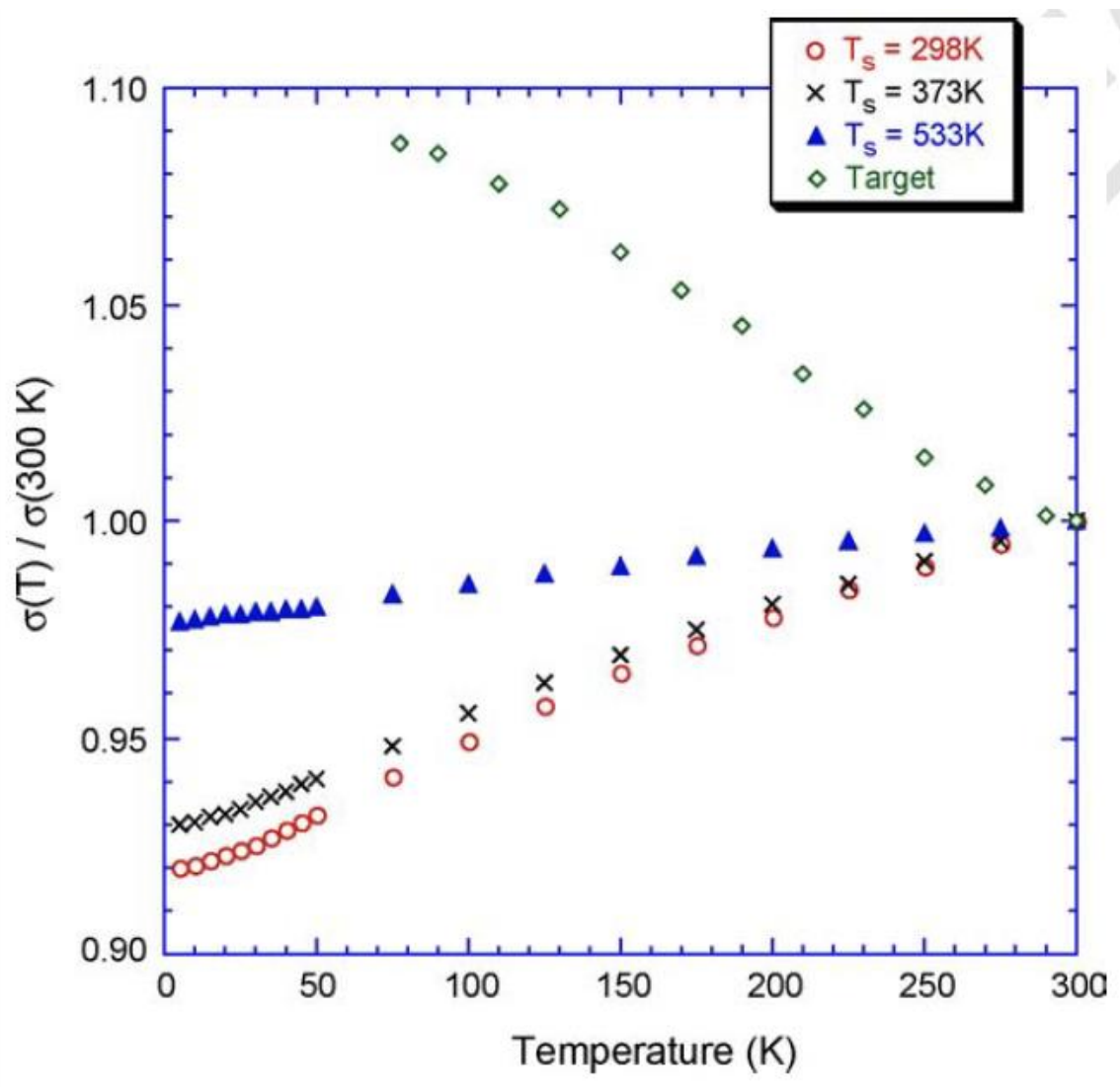

Figure 2: Temperature dependence of the normalized conductivity $\sigma / \sigma(300 \mathrm{~K})$ for the i$\mathrm{Ti}_{41.5} \mathrm{Ni}_{17} \mathrm{Zr}_{41.5}$ films and the $\mathrm{Ti}_{45} \mathrm{Zr}_{38} \mathrm{Ni}_{17}$ target. 


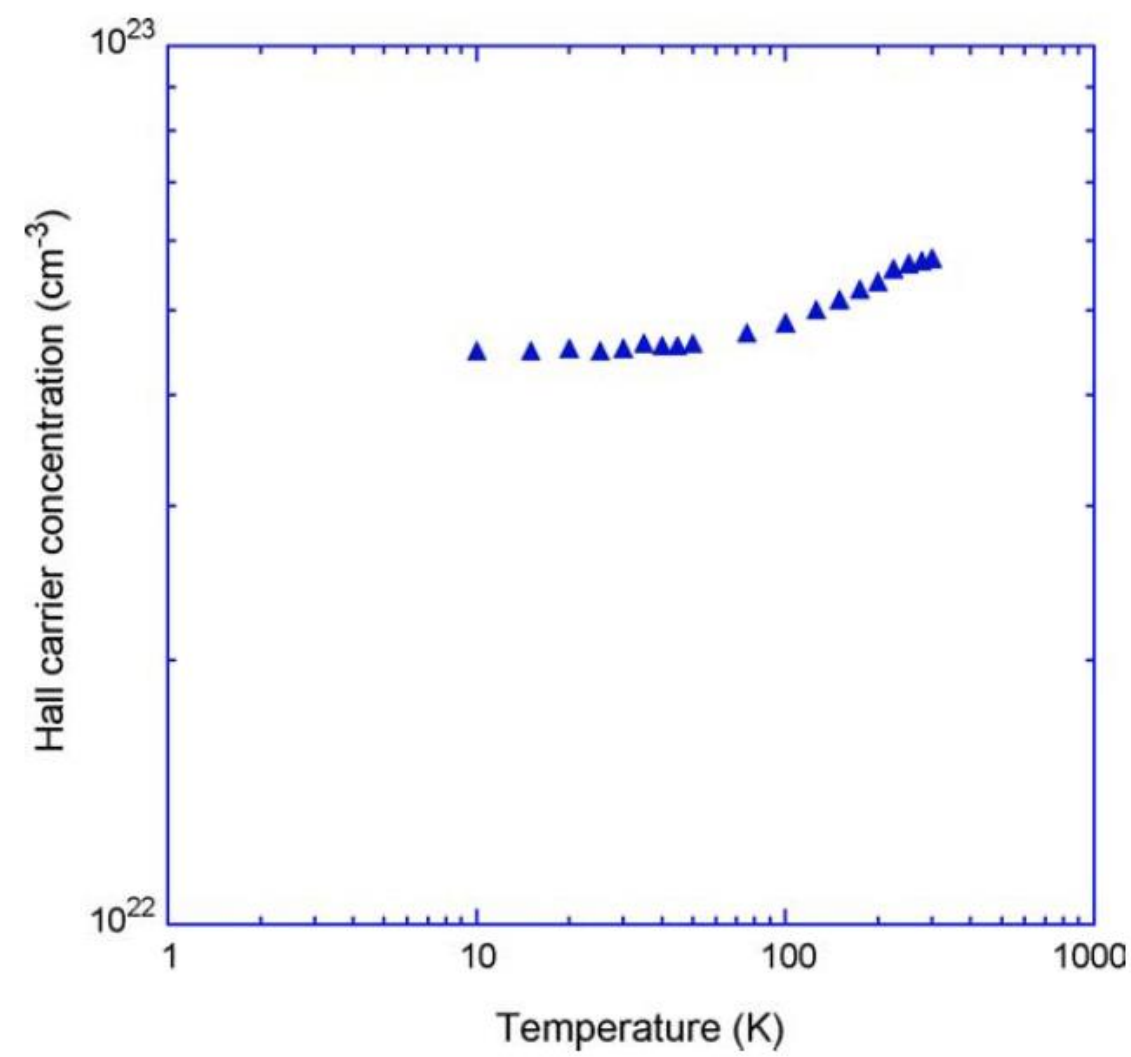

Figure 3: Temperature dependence of the Hall carrier concentration for the film prepared at $\mathrm{T}_{\mathrm{s}}$ $=533 \mathrm{~K}$. 


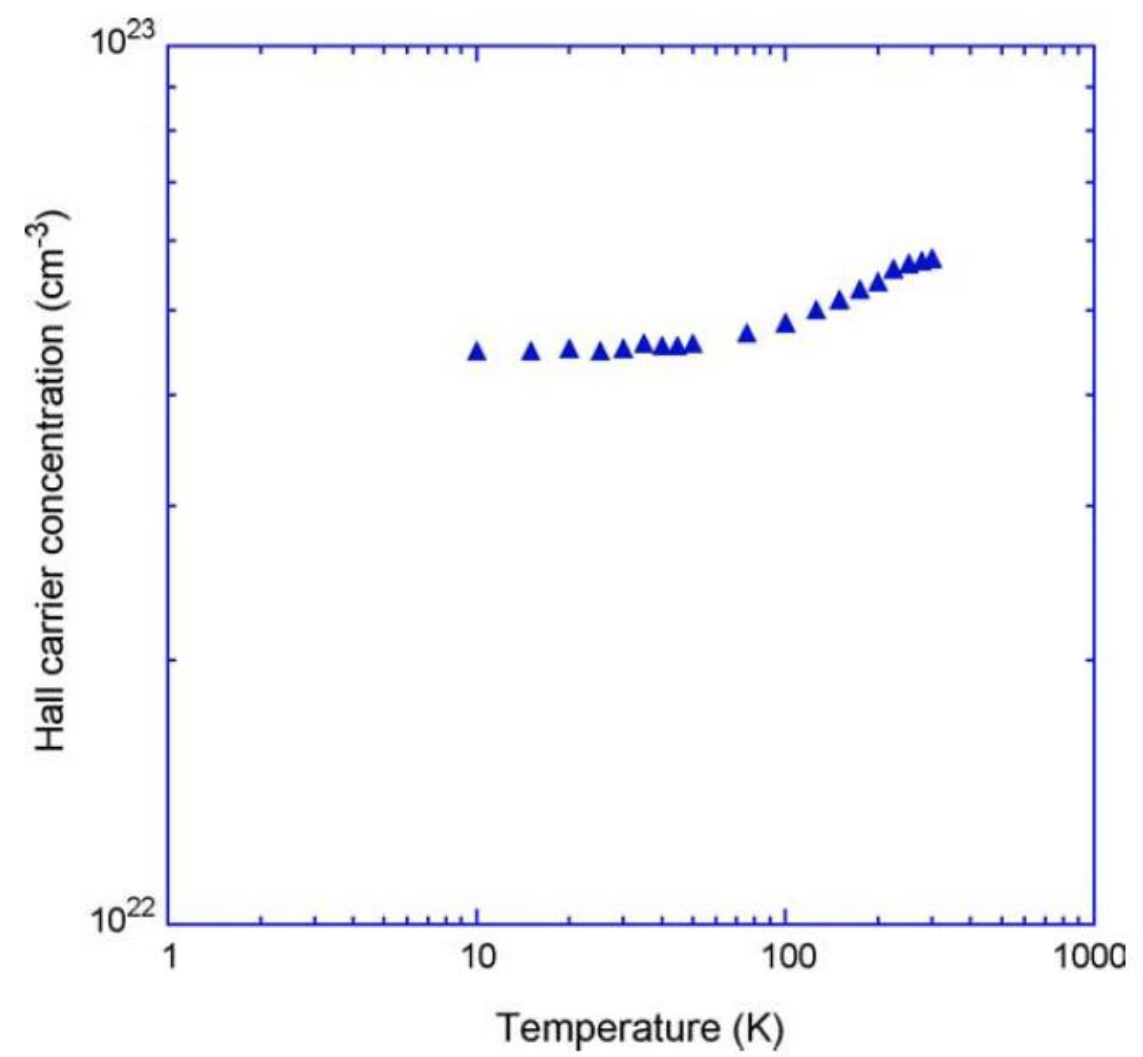

Figure 4: Magnetoresistance $\Delta \rho / \rho$ versus magnetic field for different temperatures and for the film prepared at $\mathrm{T}_{\mathrm{s}}=533 \mathrm{~K}$. 


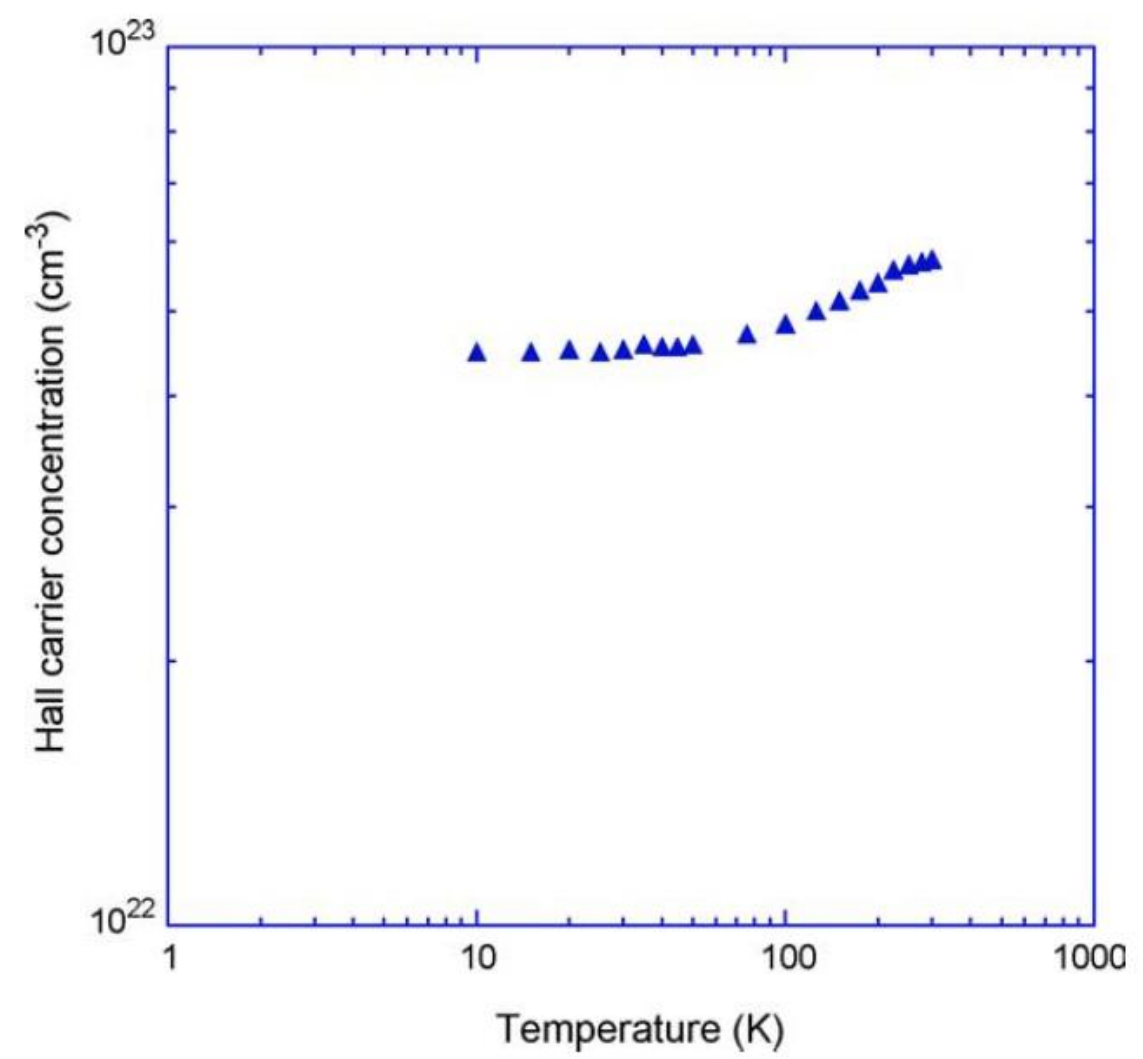

Figure 5: Temperature dependence of the thermopower $\mathrm{S}$ from 77 to $310 \mathrm{~K}$ for the i$\mathrm{Ti}_{41.5} \mathrm{Ni}_{17} \mathrm{Zr}_{41.5}$ films and the $\mathrm{Ti}_{45} \mathrm{Ni}_{17} \mathrm{Zr}_{38}$ target. 